\title{
The standardized definition of high myopia
}

\author{
Andrzej Grzybowski ${ }^{1,2}$ (D) Piotr Kanclerz ${ }^{3}$
}

Received: 10 May 2019 / Revised: 10 May 2019 / Accepted: 10 June 2019 / Published online: 21 June 2019

(C) The Author(s) 2019

Dear Editor,

We have read the article by Sanz Diez et al. [1]; however, we believe that some discussion is required. The authors have analyzed the axial length growth trend during the refractive development of Chinese schoolchildren.

In their analysis, high myopia was defined as a spherical equivalent refractive error (SER) of $\leq-5.0 \mathrm{D}$. Using such a definition is controversial, as several organizations e.g., the American Academy of Ophthalmology, the American Optometric Association or the American Association for Pediatric Ophthalmology and Strabismus define high myopia as a SER of $\leq-6.0 \mathrm{D}[2,3]$. Using a cut-off value of $-5.0 \mathrm{D}$ is not an error and is infrequently used, although the rationale for this approach is unclear. For example, Holden et al. state that they employed the cut-off value of $\leq-5.0 \mathrm{D}$, as it was the most frequently used definition in studies included in their metaanalysis [4]. However, the online supplementary material clearly states that the cut-off value of $\leq-6.0 \mathrm{D}$ or $<-6.0 \mathrm{D}$ was used in $61.0 \%$ of the included publications. We believe that employing various definitions of refractive errors in future investigations can result in an even greater inconsistency in epidemiological studies. If we agree that an atypical threshold value of $-5.0 \mathrm{D}$ can be applied, this might encourage other researchers to use different cut-off values when seeking for statistical significance in their results. Moreover, in such case, one might ask why should not we define high myopia as a SER greater than $-4.0 \mathrm{D}$ or $-7.0 \mathrm{D}$.

It is obvious that even small changes of threshold definitions of refractive errors can affect frequency estimates in epidemiological studies. Applying various cut-off values can also create both false-positive and false-negative associations

Andrzej Grzybowski

ae.grzybowski@gmail.com

1 Department of Ophthalmology, University of Warmia and Mazury, Olsztyn, Poland

2 Institute for Research in Ophthalmology, Foundation for Ophthalmology Development, 60-554 Gorczyczewskiego 2/3, Poznan, Poland

3 Private Practice, Gdańsk, Poland with risk factors [5]. Subsequently, these associations can significantly influence conclusions of epidemiological studies. Thus, we postulate employing the standardized definition of high myopia as a SER of $-6.0 \mathrm{D}$ or greater in future studies.

\section{Compliance with ethical standards}

Conflict of interest Dr. Grzybowski reports non-financial support from Bayer, non-financial support from Novartis, non-financial support from Alcon, personal fees and non-financial support from Valeant, grants from Zeiss, and personal fees and non-financial support from Santen, outside the submitted work. Dr. Kanclerz reports non-financial support from Visim and Optopol Technologies. The authors have no proprietary interest within the presented subject.

Open Access This article is distributed under the terms of the Creative Commons Attribution 4.0 International License (http:// creativecommons.org/licenses/by/4.0/), which permits unrestricted use, distribution, and reproduction in any medium, provided you give appropriate credit to the original author(s) and the source, provide a link to the Creative Commons license, and indicate if changes were made.

\section{References}

1. Sanz Diez P, Yang L-H, Lu M-X, Wahl S, Ohlendorf A (2019) Growth curves of myopia-related parameters to clinically monitor the refractive development in Chinese schoolchildren. Graefes Arch Clin Exp Ophthalmol 257:1045-1053

2. Chuck RS, Jacobs DS, Lee JK, Afshari NA, Vitale S, Shen TT, Keenan JD, American Academy of Ophthalmology Preferred Practice Pattern Refractive Management/Intervention Panel (2018) Refractive errors \& refractive surgery preferred practice pattern ${ }$. Ophthalmology 125:P1-P104

3. American Optometric Association - Care of the patient with myopia. https://www.aoa.org/documents/optometrists/CPG-15.pdf. Accessed 4 May 2019

4. Holden BA, Fricke TR, Wilson DA, Jong M, Naidoo KS, Sankaridurg P, Wong TY, Naduvilath TJ, Resnikoff S (2016) Global prevalence of myopia and high myopia and temporal trends from 2000 through 2050. Ophthalmology 123:1036-1042

5. Cumberland PM, Bountziouka V, Rahi JS (2018) Impact of varying the definition of myopia on estimates of prevalence and associations with risk factors: time for an approach that serves research, practice and policy. Br J Ophthalmol 102:1407-1412

Publisher's note Springer Nature remains neutral with regard to jurisdictional claims in published maps and institutional affiliations. 